\title{
Assessment of Diabetic Patient Waiting Time in A Primary Healthcare Clinic.
}

\author{
Shalihin SE ${ }^{a}$, Firzada $I^{b}$, Din $M H^{c}$ \\ a Mohd Shaiful Ehsan Bin Shalihin, Department of Family Medicine, Kulliyyah of Medicine, International \\ Islamic University of Malaysia. \\ ${ }^{\mathrm{b}}$ Iskandar Firzada Bin Osman, Klinik Kesihatan Jaya Gading. \\ ${ }^{c}$ Muhammad Hapizie Bin Din, Pejabat Kesihatan Daerah Kuantan.
}

\section{ABSTRACT}

Introduction: Long waiting time is a common issue complained by diabetic patients that came for an early morning appointment in a health clinic. Therefore, an audit was conducted among diabetic patients in a primary care clinic with the aim to assess the patients' waiting time and to formulate strategies for improvement. Methods: This audit was conducted for four weeks using a universal sampling method in November 2017. All diabetic patients who attended the clinic during this period were included except those who required longer period such as critically ill patients or those who came for repeat medication or procedures. The arrival and departure time for each station was captured using the modified waiting time slip, which is manually filled at every station. The waiting and consultation time for registration, screening, laboratory investigation, diabetic educator, doctor and pharmacy were recorded. The data were entered into the statistical software SPSS version 17 for analysis. Results: Results showed that all patients were registered within 11.0 minutes $(S D=2.52 \mathrm{~min}$ ). Average total waiting time to see a diabetic educator and a doctor was 20.9 minutes $(S D=15.53 \mathrm{~min})$ and 33.23 minutes $(S D=27.85 \mathrm{~min})$, respectively. Average waiting time for other stations was less than 10 minutes. Average total time spend in the clinic for a diabetic patient was 107.58 minutes, which is comparable to a non-diabetic patient. The identified problems were due to the poor tracing and filing system. Conclusion: Improvement strategies recommended include enforcing early file tracing prior to appointment and providing a checklist for consultation by doctors and diabetic educators.

KEYWORDS: Clinical audit, diabetic patient waiting time, consultation time, primary care.

\section{INTRODUCTION}

Patient satisfaction is important and has been recognized as the main indicator of the quality of care. It is influenced by patients, physicians and clinical practices' characteristics including patients' waiting time management. ${ }^{1}$ Till date, patients still experience unacceptable levels of waiting time in the clinic even with the advancement in technological developments in medical care such as organisation empowerment and facilities development driven by the health organization and government agencies. ${ }^{2}$

Corresponding Author:

Asst. Prof. Dr. Mohd Shaiful Ehsan Bin Shalihin Department of Family Medicine, Kulliyyah of Medicine, International Islamic University of Malaysia, Kuantan Campus, Jalan Sultan Ahmad Shah, 25200 Kuantan, Pahang.

Tel No : +60177948679

Email : shaifulehsan@iium.edu.my
Long waiting time is a common issue brought up by diabetic patients mainly in a busy health clinic. ${ }^{3,4}$ Furthermore, diabetic patients are among the major group of patients that attended the clinic early morning for multiple routine procedures such as capillary glucose measurement, weight measurement, blood pressure measurement, venous blood taking, diabetes educator screening and advice, medical doctor assessment and finally pharmacy checkpoint before they complete the whole consultation day. This complex consultation cycle would definitely contribute towards patients' dissatisfaction if the duration of the waiting time is long for each station. ${ }^{3,4}$ Thus, literature in diabetes has increasingly focused on the quality of care and its measurement, which not only look at the diabetes control but also patients' perception towards the long term holistic care and treatment including satisfactory clinic services such as shorter waiting time. ${ }^{3}$ 
Numerous studies and researches have demonstrated a reverse relation between waiting time and patient satisfaction including quality of care. ${ }^{1-4}$ This is indeed one of the main reasons for waiting time is a major concern for hospital administrators and policymakers. It reflects the organisational efficiency, quality performance and excellent management flow. ${ }^{3-5}$ Furthermore, the Ministry of Health also has announced customer policy on the waiting time duration should be within 30 minutes to be served by the medical staff. ${ }^{6}$ Therefore, it is important for an audit to be carried out in order to observe the required performance.

Previous studies have proved that the high number of patients, long distance between each station or units that the patients need to visit, poor communication between patients and healthcare providers and the low number of manpower affect the prolonged patients' waiting time. ${ }^{7,8}$ It is a true scenario for diabetic patients in which their numbers are the highest among the group of patients with chronic diseases who need to undergo follow up in a primary care centre. There are several stations need to be visited by the diabetic patients before entering the doctor's consultation room.

Nevertheless, the relationship between the quality of diabetes care and patient satisfaction including appropriate clinic time spent by the patient is poorly understood and it requires further elaboration especially in our local government health clinic setting. ${ }^{3,4}$ Furthermore, there is insufficient published data to support the acceptable waiting and consultation time in the primary healthcare clinics in Malaysia in terms of managing diabetic patients that require a thorough assessment at each visit. Therefore, this audit aims to assess diabetic patients' waiting time in a public clinic in order to formulate strategies for improvement. By systematically breaking down processes and identifying the problem areas, targeted changes will be implemented. In this audit, the diabetic patients' results are compared with non-diabetic patients to prove any significant differences between those having a higher number of stations to be visited as compared to those with a fewer number of visit stations.

\section{MATERIAL AND METHODS}

This audit was conducted at a primary care clinic in Kuantan District from $6^{\text {th }}$ November 2017 until $1^{\text {st }}$
December 2017. A four-week study period was perceived as sufficient for data collection to include clinical management involving family medicine specialists (FMS), medical officers (MO) and diabetic educators of active type 2 diabetic patients follow up. The objectives of this study are: 1) to calculate the average and maximum waiting time in each station, 2) to compare the waiting time between diabetic patient and non-diabetic patient and 3) to identify any improvement needed for diabetic patient flow in the clinic. The non-diabetic patients' results are compared with diabetic patients to prove any significant differences between those two categories. These two groups are the main patients who waited early morning in the government health clinic for an appointment. Therefore, the magnitude of such differences between those having a higher number of stations to be visited (diabetic patients) compared to those with a fewer number of visit stations (non-diabetics) is to be examined.

\section{CLINIC SETTING}

The primary care clinic is situated in a district of Kuantan at east coast region of Malaysia. This clinic is situated 20 kilometres from Hospital Tengku Ampuan Afzan Kuantan. It provides health services for the surrounding multi-ethnic community with an estimated population of 80000 people. Majority of the population were Malays followed by Chinese and other Bumiputras, Indian and a small minority of immigrants. Almost half of the population obtained at least a secondary level of education and nearly two-thirds were either self-employed, unemployed or retired. Nearly half of the population have a total monthly household income of less than RM2500. There are army camp, police quarters, few factories, schools, and three palm oil Felda estates within that area.

In 2017, the total annual clinic attendees for new and old cases in this primary care clinic were 89,113 patients, with an average of 200 to 300 patient attendance per day. From this data, an average of 30 -50 attendance per day were active diabetic patients. In terms of allocation of staff and flow, there is a staff allocated at the registration and appointment counter and another staff at the payment counter. There are four consultation rooms with one Family Medicine Specialist (FMS) and six medical officers (MOs). Following the integration of the patient-centred approach, any medical officer is 
accountable to see diabetic patients regardless of any consultation rooms. Despite "follow-up" patients were given a specific appointment date, a "no wrong door" policy was also practiced, in which patients will be entertained without any prejudice even if they did not follow the appointment date. The walkin patients who attended the clinic would be seen by any available medical officers.

The flow of stations needed to be attended by our diabetes patients in our clinic in 2017 is as follow:

Patient arrived at clinic $\rightarrow$ Submit diabetic follow up card at the registration counter and take a registration number $\rightarrow$ Patient to wait for the diabetic book at the waiting area in front of the registration counter $\rightarrow$ Diabetic record book received and the patient goes to the laboratory - Waiting area at the laboratory - Capillary sugar check at the laboratory $\rightarrow$ Waiting area at the laboratory before seen by a diabetic educator Review by the diabetic educator $\rightarrow$ Waiting area at the outpatient department $(\mathrm{OPD}) \rightarrow$ Blood pressures, weight, height, $\mathrm{BMI}$ measurement at the screening counter in the outpatient department $(O P D) \rightarrow$ Waiting area at the outpatient department $(O P D) \rightarrow$ Treatment room and / or doctor's consultation room $\rightarrow$ Waiting area at pharmacy

$\rightarrow$ Seen by the pharmacist $\rightarrow$ Complete consultation and return home.

\section{SAMPLING AND RECRUITMENT}

The study was conducted using a universal sampling method. All diabetic patients who attended the outpatient department of this primary care clinic during the study period in the morning session were included in the study. The exclusion criteria included patients who were critically ill requiring referral or admission, those who came for repeat medications, investigations or procedures only without seeing a doctor and those who were involved with physiotherapy session on the same day. Those newly diagnosed diabetic patients were also excluded from the audit.

\section{TRAINING OF STAFF FOR THE AUDIT}

A short briefing session among all staff was held prior to the audit to ensure proper time recording on the timing slip. WhatsApp messages were sent to all doctors and staff prior and during the audit period. A reminder to use a waiting time slip, which is modified from the Clinic E-masa form was given to staff before and during the audit period. Each time an issue or problem occurred, the staff is encouraged to write a message in the WhatsApp group to alert all the staffs during the audit.

\section{SETTING STANDARDS FOR ACCEPTABLE WAITING TIME PRACTICE}

The standard for this audit was set according to the recommendation from the Malaysian Ministry of Health's patient's charter, which targeted that the waiting time for patients to be seen by the first provider in hospital outpatients and health clinics should not exceed 30 minutes upon arrival with a standard of $80 \%$ achievement target.

\section{DATA COLLECTION PROCESS}

The process of time recording is demonstrated in Figure 1 starting from the time the patient arrived at the registration counter at the outpatient department. Once the patient has printed the QMS number, a timing sheet containing the station's details and 'time in' and 'time out' will be given to be filled by the dedicated staff at every station. The timing sheet will be stapled on the patients' registration card and carried along to every station the patient attended. The time of arrival and departure at each station was captured using the sheet by the health care providers in front of the patient.

For example, the doctor's pre-consultation waiting time will be recorded by the staff in the vital signs assessment area. Meanwhile, the doctor's consultation waiting time will be recorded by the doctor (FMS or MO). Each diabetic patient is paired with a non-diabetic patient in order to assess the time difference between the two groups. All relevant data were recorded manually in the audit form before being entered into the SPSS version 17.0 to be analysed. Descriptive analysis was conducted with independent $\mathrm{T}$-test for significance and $\mathrm{p}$-value was set at $<0.01$. The results of the audit were presented at the clinical meeting and recommendations together with improvements were made.

\section{RESULTS}

About $10 \%$ of our registered diabetic patients involved in this audit and they were mainly elderly female patients, Malay and came for follow up. 


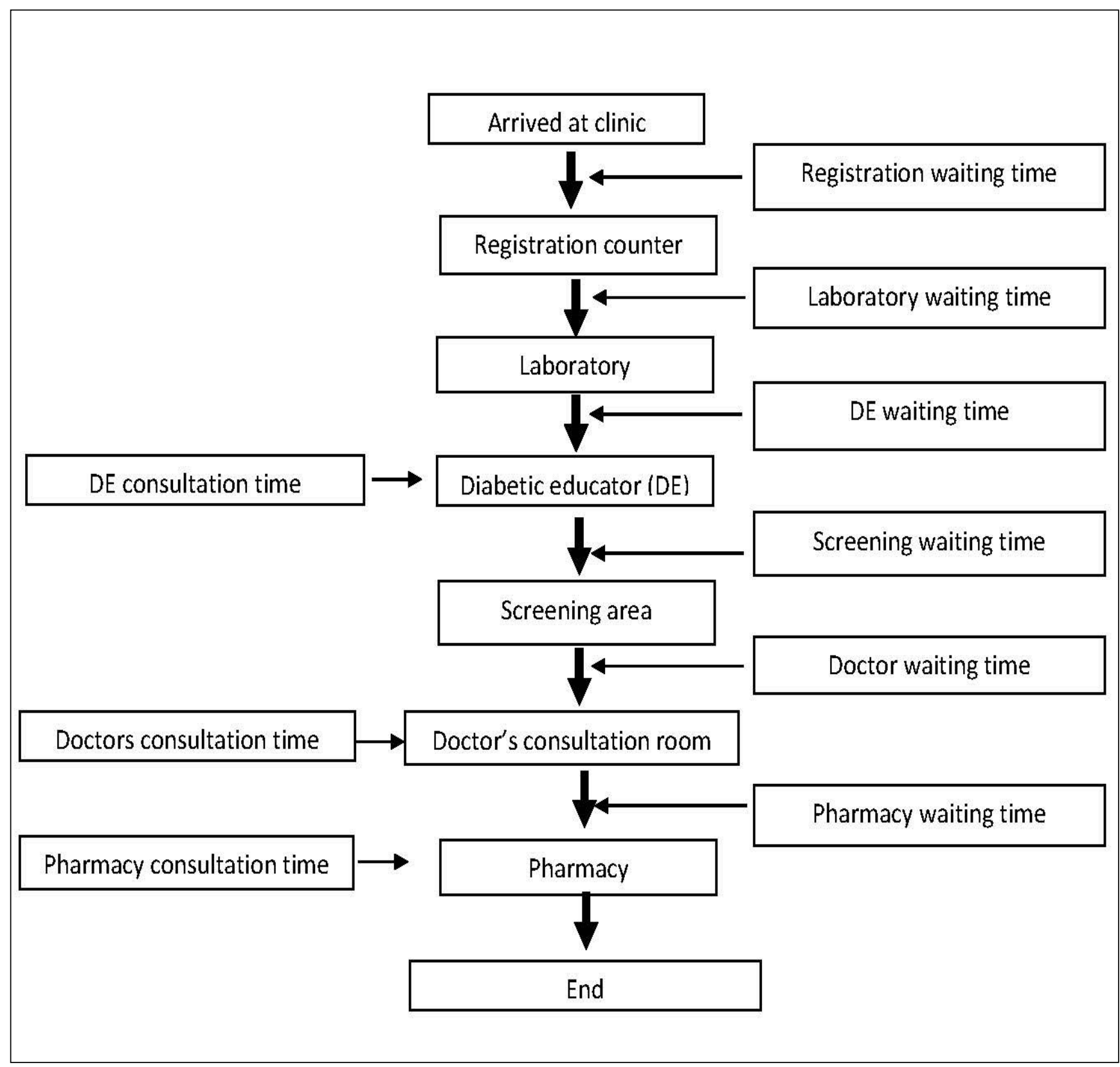

Figure 1: Chart showing patient's flow of movement in the primary care clinic from arrival until departure with related capture of waiting and consultation time.

Further details of the demographic data of the diabetic patients are summarized in Table 1.

Results showed that on average, all patients were seen within 11.0 minutes $(S D=2.52 \mathrm{~min}$ ) by the first health care provider encountered in the clinic. Even though most stations' waiting time were recorded within 10 minutes duration, the average total waiting time to see a diabetic educator and doctor were the longest duration recorded, which were 20.9 minutes $(S D=15.53 \mathrm{~min})$ and 33.23 minutes $(S D=27.85 \mathrm{~min})$, respectively. The maximum time recorded was up to 124 minutes and this contributes to the longest waiting time. The timing parameter is significantly shorter for a diabetic patient if diabetic educator's station is excluded as shown in Table 2.

Nevertheless, both diabetic patient and non-diabetic patient groups contributed to the crowded scenarios in the Outpatient Department (OPD) in the early morning. Table 3 summarized the average waiting and consultation time of diabetic patients versus non-diabetic patients with a $\mathrm{p}$-value of Paired Sample T-Tests Sig 2 tailed of 0.794 . The waiting time difference between diabetic and non-diabetic patients was found to be statistically significant during registration and laboratory procedure as shown in Table 4. 
Table 1. Demographic details of diabetes patients in this study

\begin{tabular}{lll}
\hline Variables & Category & Frequency $\mathbf{n}(\%)$ \\
\hline \multirow{2}{*}{ Age } & $\begin{array}{l}\text { Less than } 60 \\
60 \text { and more }\end{array}$ & $120(43 \%)$ \\
& & \\
& Male & $160(57 \%)$ \\
Gender & Female & $165(59 \%)$ \\
& Malay & $272(97 \%)$ \\
Ethnicity & $\begin{array}{l}\text { Chinese } \\
\text { Indian }\end{array}$ & $2(1 \%)$ \\
& & $249(89 \%)$ \\
Visit type & Follow up & $31(11 \%)$ \\
& Walk in & \\
\hline
\end{tabular}

\section{DISCUSSION}

In this four weeks' audit, about $10 \%$ of our registered diabetic patients were involved and this is comparable to other studies. ${ }^{1,3}$ The study results also shown that on average, all patients were seen within 11.0 minutes by the first encountered health care providers, which is better than other studies. ${ }^{1,3,5}$ This clinic also achieved a good average waiting time of 29.97 minutes to be seen by the doctor for diabetic patients. This study indeed proved that the clinic has achieved the target waiting time adopted by the Ministry of Health patient's charter. ${ }^{6}$ The possible reason for such improvement is because the audit is performed at the end of the year, in which multiple

Table 2: Average waiting and consultation time of diabetic patient

\begin{tabular}{lccc}
\hline Station & $\begin{array}{c}\text { Average } \\
\text { time } \\
(\text { min })\end{array}$ & $\begin{array}{c}\text { Standard } \\
\text { Deviation } \\
(\text { min })\end{array}$ & $\begin{array}{c}\text { Max. time } \\
\text { (min) }\end{array}$ \\
\hline $\begin{array}{l}\text { Registration } \\
\text { counter waiting } \\
\text { time }\end{array}$ & 0.54 & 0.69 & 3.0 \\
$\begin{array}{l}\text { Screening counter } \\
\text { waiting time }\end{array}$ & 6.46 & 5.91 & 18.0 \\
$\begin{array}{l}\text { Lab waiting time } \\
\begin{array}{l}\text { Glucometer } \\
\text { procedure time }\end{array}\end{array}$ & 7.47 & 7.25 & 24.0 \\
$\begin{array}{l}\text { Diabetic educator } \\
\text { waiting time }\end{array}$ & 20.90 & 15.53 & 62.0 \\
$\begin{array}{l}\text { Diabetic educator } \\
\text { consultation time }\end{array}$ & 9.52 & 8.47 & 33.0 \\
$\begin{array}{l}\text { Doctor waiting time } \\
\begin{array}{l}\text { Doctor consultation } \\
\text { time }\end{array}\end{array}$ & 29.97 & 27.18 & 103.0 \\
$\begin{array}{l}\text { Pharmacy waiting } \\
\text { time }\end{array}$ & 10.29 & 9.22 & 43.0 \\
$\begin{array}{l}\text { Pharmacy } \\
\text { consultation time }\end{array}$ & 7.86 & 8.58 & 44.0 \\
$\begin{array}{l}\text { Total time spend in } \\
\text { clinic }\end{array}$ & 107.58 & 87.21 & 195.0 \\
\hline & 7.81 & 2.86 & 14.0 \\
\hline
\end{tabular}

staff had attended in-house training and courses to improve clinic services mainly involving the supporting staffs. The clinic also practices dual record system consists of home based-card and clinic based-card. In this system, only diabetic cards are stored at the counter while other outpatient cards were kept by the patients and this reduces the waiting time during registration and searching for cards by the staff.

In comparison between all stations for diabetic patients, the average waiting time in the clinic is noted to be the longest to see a diabetic educator and a doctor, with the maximum time reaching up to 103 minutes. These indeed have contributed to the significant longer waiting time among the diabetic patients in the clinic. This is expected as the diabetic patients require thorough explanation and counselling by the health care providers. The counselling not only focused on the sugar control but also towards the diet, physical activity, comorbid, and psychosocial health of the patients.

Table 3: Average Waiting \& Consultation Time of Diabetic Patients versus Non-diabetic Patients

\begin{tabular}{lll}
\hline Station & Diabetic $(\mathrm{min})$ & $\begin{array}{l}\text { Non diabetic } \\
(\mathrm{min})\end{array}$ \\
\hline $\begin{array}{l}\text { Registration } \\
\text { counter waiting } \\
\text { time }\end{array}$ & $0.54(\mathrm{SD}=0.69)$ & $2.44(\mathrm{SD}=3.63)$ \\
$\begin{array}{l}\text { Screening counter } \\
\text { waiting time }\end{array}$ & $6.46(\mathrm{SD}=5.91)$ & $10.29(\mathrm{SD}=12.62)$ \\
$\begin{array}{l}\text { Lab waiting time } \\
\begin{array}{l}\text { Glucometer } \\
\text { procedure time }\end{array}\end{array}$ & $7.47(\mathrm{SD}=7.25)$ & $15.00(\mathrm{SD}=0.51)$ \\
$\begin{array}{l}\text { Doctor waiting } \\
\text { time }\end{array}$ & $29.97(\mathrm{SD}=27.18)$ & $37.17(\mathrm{SD}=28.72)$ \\
$\begin{array}{l}\text { Doctor } \\
\text { consultation time }\end{array}$ & $10.29(\mathrm{SD}=9.22)$ & $9.33(\mathrm{SD}=7.75)$ \\
$\begin{array}{l}\text { Pharmacy waiting } \\
\text { time }\end{array}$ & $7.86(\mathrm{SD}=8.58)$ & $6.21(\mathrm{SD}=5.17)$ \\
$\begin{array}{l}\text { Pharmacy } \\
\text { consultation time }\end{array}$ & $7.81(\mathrm{SD}=2.86)$ & $7.20(\mathrm{SD}=5.01)$ \\
$\begin{array}{l}\text { Total time spend } \\
\text { in clinic }\end{array}$ & $\begin{array}{l}107.58 \\
(\mathrm{SD}=87.21)\end{array}$ & $\begin{array}{l}130.14 \\
(\mathrm{SD} 115.92903)\end{array}$ \\
\hline
\end{tabular}

The study results shown that the difference between diabetic and non-diabetic patients' average waiting time is not statistically significant. However, nondiabetic patients waited longer compared to diabetic patients for registration and laboratory procedure time. These findings are proven to be statistically significant (Table 4). This data will be the strongest 
evidence to correct the misconception by the public and health care providers regarding the sole contribution of longer waiting time by the diabetic patient alone.

The diabetic flow is a complex process, however, the clinic staffs were able to utilize the time professionally to make it useful and as appropriate as for another type of patients. This might be contributed by the awareness of the health care providers on the risk of acute hypoglycaemia and hyperglycaemia of diabetic patients if waited longer in the clinic without meals. ${ }^{10}$ Long waiting time in a busy outpatient department can also increase the risk of hypoglycaemia in view of changes and delays in the mealtime of the diabetic patients. ${ }^{11-13}$ Therefore, good time management in dealing with diabetic patients would prevent the occurrence of moderate to severe hypoglycaemia in the clinic's waiting area.

Table 4: Significant Difference of Average Time between Diabetic and Non-diabetic Patients

\begin{tabular}{lllllll}
\hline & & & & \multicolumn{2}{c}{$95 \%$ confidence interval } \\
\hline & Sig & Sig 2 tailed & Mean difference & Standard error & Lower & Upper \\
Registration & 0.000 & 0.003 & -1.89946 & .61024 & -3.12012 & -.67880 \\
Counter & & .016 & -1.89946 & .73474 & -3.41213 & -.38679 \\
Lab & 0.000 & 0.002 & -35.73810 & 9.94709 & -56.42420 & -15.05199 \\
procedure & & .515 & -35.73810 & 37.53116 & -508.89572 & 437.41952 \\
\hline
\end{tabular}

Nevertheless, this study observes a trend of longer stay among the non-diabetic patients in the clinic compared to diabetic patients and this contributes to the crowded scenarios in the early morning at the outpatient department. Interestingly, the pharmacy's consultation time is recorded to be longer for the diabetic patient compared to nondiabetic patient. This might reflect the true situation in another clinic as well in view of the complexity of the diabetic medications that require a longer time for counselling such as the technical usage of the insulin. ${ }^{10}$ In fact, pharmacists play an important role in contributing towards good control of patient's diabetes status and quality of life. ${ }^{14-15}$ They are the final gatekeeper to double-check the patient's understanding before the patients are allowed to end the consultation cycle of the clinic visit.

Post audit discussion and brainstorming meeting among diabetic clinic's committee team has been done in order to identify the specific contributing factors to the above scenarios mainly from the doctor and diabetic educator's station. One important reason is that there is no specific mutual agreement on the topics that need to be covered for counselling by the diabetic educator and doctor on the same visit day by the patient. This causes the topics and management issues been highlighted redundantly causing unproductive time usage.
Moreover, the topics that have been covered were not listed by the diabetic educator and the same was practiced by the doctor. Therefore, it is clear that there is no proper communication between these two providers.

In order to overcome this issue, a checklist was attached on the front cover of the diabetes record book for each diabetic patient. All health care providers will need to use the checklist and mark the topics that have been included during the counselling. With these modifications in place, the doctors will not elaborate on the topics that have been counselled by diabetic educators. These will reduce the time for consultation and therefore, improving overall patients' waiting time.

Post audit discussion also has managed to identify poor tracing and filing system as the potential contributors for the longest time spent in the clinic for both diabetic and non-diabetic patients, especially in registration and laboratory procedures. Therefore, in order to overcome such situation, a proper tracing system has been initiated involving cards tracing one week earlier for the next follow up and the cards are stored in the basket available in the diabetic educator's room. Diabetic educator and staff will also provide a reminder in the form of 'phone call' to the patient if the patient did not turn up on the follow-up date before returning the 
diabetic book to the counter. Each diabetic patient is reminded to follow the appointment date accordingly. As a motivation, those with good diabetic control and with good adherence to the appointment date will be given a token of appreciation. Scheduling is important to ensure smooth clinic flow. A study of the scheduled model found that patients who were given an appointment time and arrived accordingly had shorter waiting time than those who walked in without an appointment. ${ }^{9}$ Previous studies also showed that reminder system had successfully able to improve patient adherence to appointment schedule and treatment. ${ }^{16,17}$ All these measures are expected to improve the patients' waiting time in the clinic.

\section{CONCLUSION}

Primary care providers play a major role in promoting a higher level of satisfaction by practicing good communication with patients within the appropriate time. Improvement strategies recommended include enforcing early file tracing prior to the appointment date and providing a checklist for consultation for doctors and diabetic educators. 30 minutes duration of patients' charter as recommended by the Ministry of Health is indeed reasonable and achievable by the complex diabetic patients' flow system.

\section{REFERENCES}

1. Mohammed AH, Alian AA, Basyirah AR, Saleh KT, Fahad S, Noman UH and Hisham A. Assessment of General Public Satisfaction with Public Healthcare Services in Kedah, Malaysia. Australasian Medical Journal. 2014; 7(1): 35-44.

2. Loh I. Long Waiting Time at Hospital Unacceptable, Says Activist. TheStar Online. 2018.

3. Michela T, Panagiotis $\mathrm{P}$, George $\mathrm{S}$, George $\mathrm{O}$ and Alistair M. Improving Quality Care For Diabetes In The Community: What Do Cypriot Patients Want? International Journal for Quality in Health Care. 2018; 30(6): 443-449.

4. Emily LH. Improving Waiting Time and Operational Clinic Flow in a Tertiary Diabetes Center. BMJ Quality Improvement Reports. 2014; 2(2).

5. Ugenthiri N, Gerry F, Joel MD and Michael R. Time to Wait: A Systematic Review of Strategies That Affect Out-Patient Waiting Times. Australian Health Review. 2018; 42: 286-293.
6. Pekililing Ketua Pengarah Kesihatan Malaysia Bil 2/2008, Pemantauan Waktu Menunggu Dalam Tempoh 30 Minit Di Jabatan Pesakit Luar Hospital Dan Klinik Kesihatan.

7. Farhad H, Ghahraman M, Fatemeh D, Fahimeh F, Esmaeil R. The Factors Affecting the Waiting Time of Outpatients in the Emergency Unit of Selected Teaching Hospitals of Tehran.

Electronic Journal of General Medicine. 2018; 15 (3).

8. Shyamkumar S and Rakchanok N. Determinants of Hospital Waiting Time for Outpatient Care in India: How Demographic Characteristics, Hospital Ownership, and Ambulance Arrival Affect Waiting Time. International Journal of Community Medicine and Public Health. 2018; 5(7).

9. Jing S, Qian L, Pengyu Z, Qiongyao Z, Kai X, Huiying $\mathrm{C}$, Cecile $\mathrm{JH}$, Mark $\mathrm{S}$ et al. Reducing Waiting Time and Raising Outpatient Satisfaction in a Chinese Public Tertiary General Hospital-An Interrupted Time Series Study. BMC Public Health 2017; 17(668).

10. Jeffery DH, Yosi W, Bruce $S$ and Kreshnik H. The role of the pharmacist in the management of type 2 diabetes: current insights and future directions. Integrated Pharmacy Research and Practice 2017; 6:15-27.

11. Javier M and Doron S. Hypoglycemia. The American Journal of Medicine. 2014; 127: S17S24.

12. Katherine LG. Hypoglycemia Prevention in Hospital Patients: A Quality Improvement Project to Prevent Severe and Recurrent Hypoglycemia. Clinical Diabetes Journals. 2016; 34(4): 193-196.

13. Robert WL, Deborah OL and Judit I. Preventing Hypoglycemia in Type 2 Diabetes. The Journal of Clinical Endocrinology \& Metabolism' 2018; 103 (4): 1265-1268.

14. Javedh $S$, Jennifer $F$ and Laxminarayana $S$. Evolving Role of Clinical Pharmacist in The Management of Diabetes Mellitus. International Journal of Research in Medical Sciences. 2015; 3 (6): 1305-1308.

15. Shazia QJ, Mohammand JS, Bareera R and Akshaya SB. Evaluation of the Involvement of Pharmacists in Diabetes Self-Care: A Review from the Economic Perspective. Front Public Health. 2018; 6(244).

16. Justin HT, Barathi R, Raveen S, Chui YL, Selena $\mathrm{SN}$, Nooraini J, Gek ML, May CS, Kee CN and Thaschawee A. A Quality Improvement Project to Reduce Waiting Time for Pediatric Outpatient Referral Clinics in Singapore. Proceedings of 
Singapore Healthcare. 2017; 26(4): 224-229.

17. Liu Q, Abba K, Alejandria MM, Sinclair D, Balanag VM and Lansang MAD. Reminder Systems to Improve Patient Adherence to Tuberculosis Clinic Appointments for Diagnosis and Treatment (Review). Cochrane Database of Systematic Reviews.2014; (11). 